\title{
Primeiro relato de atividade patogênica de Hirsutella thompsonii (Fischer) sobre o ácaro-da-erinose-da-lichia Aceria litchii (Keifer) ${ }^{1}$
}

\section{First report of pathogenic activity of Hirsutella thompsonii (Fischer) on the litchi erineum mite Aceria litchii (Keifer)}

\author{
Pedro Renan Ferreira Picoli²; Marineide Rosa Vieira ${ }^{3 *}$
}

\begin{abstract}
Resumo
O ácaro-da-erinose-da-lichia Aceria litchii (Keifer) é encontrado em todas as regiões produtoras atacando folhas e inflorescências de plantas de lichia. $\mathrm{O}$ ataque de $A$. litchii em folhas jovens causa a produção de eríneos na superfície inferior, que posteriormente se transformam em galhas de coloração marrom e aparência aveludada. Ataques severos podem provocar queda de folhas e destruição dos ponteiros afetando diretamente a produção. No ano de 2009 foi registrada uma grande infestação da praga em plantas de lichia (Litchi chinensis Sonn.) no município de Casa Branca, São Paulo Brasil $\left(21^{\circ} 27^{\prime} \mathrm{O} ; 47^{\circ} 02^{\prime} \mathrm{S} ; 679\right.$ metros de altitude). No mês de junho, muitas galhas provocadas pela infestação do ácaro apresentavam um micélio de coloração branca e muitos eriofídeos mortos. $\mathrm{O}$ fungo foi identificado como Hirsutella thompsonii (Fischer). Os resultados sugerem que as galhas podem facilitar o desenvolvimento do fungo e a sua permanência nas plantas. Dessa forma, a possibilidade do controle biológico de $A$. litchii com $H$. thompsonii deve ser investigada.
\end{abstract}

Palavras-chave: Litchi chinensis, Acari, controle biológico

\begin{abstract}
The litchi erineum mite, Aceria litchii (Keifer) is found in all producing regions attacking leaves and flowers of litchi plants. The mite attack young leaves and causes the erinea on leaf surface, which later become brown galls with velvety appearance. Severe attacks can cause leaf drop and destruction of branches end directly production affecting. In 2009 year it was registered a heavy infestation of the pest on litchi plants (Litchi chinensis Sonn.) in the municipality of Casa Branca, São Paulo, Brazil $\left(21^{\circ} 27^{\prime} \mathrm{O} ; 47^{\circ} 02^{\prime} \mathrm{S} ; 679 \mathrm{~m}\right.$ altitude). In June, many galls caused by mite infestation showed a mycelium of white coloration and many eriophyid dead. The fungus was identified as Hirsutella thompsonii (Fischer). The results suggest that galls may facilitate the fungus development and its permanence on the plants. Thus, the possibility of mite biological control with $H$. thompsonii should be investigated.

Key words: Litchi chinensis, Acari, biological control, erinose
\end{abstract}

\footnotetext{
${ }^{1}$ Parte da dissertação do primeiro autor apresentada ao Programa de Pós-graduação em Agronomia, Universidade Estadual Paulista, UNESP, para obtenção do título de Mestre em Agronomia.

${ }^{2}$ Eng $^{\circ}$ Agr ${ }^{\circ}$, Mestre em Agronomia. E-mail: renan_agro@yahoo.com.br

${ }^{3}$ Prof $^{\mathrm{a}}$ do Dept ${ }^{\mathrm{o}}$ de Fitossanidade, Engenharia Rural e Solos, Universidade Estadual Paulista, UNESP, Ilha Solteira, SP. E-mail: marineid@bio.feis.unesp.br

* Autor para correspondência
} 
O ácaro Aceria litchii (Keifer) é encontrado em todas as regiões produtoras atacando folhas e inflorescências de plantas de lichia (Litchi chinensis Sonn.). O ataque, quando severo, além de promover a queda de folhas pode causar a destruição dos ponteiros afetando diretamente a produção. Infestações intensas também podem provocar a morte de plantas jovens (MARTINS; BASTOS; SCALOPPI JUNIOR, 2001).

$\mathrm{O}$ ataque de $A$. litchii em folhas jovens causa a produção de eríneos na superfície inferior que posteriormente se transformam em galhas de coloração marrom e aparência aveludada. Estas galhas são como pequenas bolhas que podem eventualmente cobrir a folha por inteiro, causando encrespamento. Em muitos casos toda a superfície foliar pode ser deformada (SIDIQQUI, 2002; SINGH; BABITA, 2002).

Fungos patogênicos a ácaros fitófagos tem sido relatados por vários autores, inclusive para a família Eriophyidae. Em seringueira, o fungo Hirsutella thompsonii (Fischer) já foi registrado infectando o ácaro Calacarus heveae Feres (Eriophyidae) em clones cultivados no município de Itiquira, MT, provocando alta mortalidade dos ácaros (TANZINI et al., 2000). Nesse mesmo local, a quantificação mensal da taxa de infecção de $H$. thompsonii sobre $C$. heveae e Phyllocoptruta seringueirae Feres (Acari, Eriophyidae) em seringueiras do clone PB 235, registrou valores próximos de 45 e $25 \%$ respectivamente (DEMITE; FERES, 2008), mostrando seu potencial como agente regulador das populações dessas espécies.

Este trabalho é o primeiro relato da ação patogênica de $H$. thompsonii sobre A. litchii, o-ácaro-da-erinose-da-lichia. As observações foram feitas em experimento realizado no município de Casa Branca, SP, Brasil, em área comercial, com coordenadas geográficas de $21^{\circ} 27^{\prime} \mathrm{O}$ e $47^{\circ} 02^{\prime} \mathrm{S}$ e 679 metros de altitude. O clima do município, descrito por Köppen como Aw, tropical com estação seca no inverno, apresenta temperatura média anual de $21,5^{\circ} \mathrm{C}$ e precipitação média anual de $1310 \mathrm{~mm}$ (CENTRO DE PESQUISAS METEOROLÓGICAS E CLIMÁTICAS APLICADAS À AGRICULTURA, 2011).

A ocorrência de $A$. litchii e os danos provocados foram acompanhados em quatro árvores adultas, de 12 anos de idade, da variedade Bengal, no período de agosto de 2008 a dezembro de 2009. Nessa área, a infestação de $A$. litchii teve início em agosto de 2008 com pico populacional em outubro e novembro. Como consequência, a produção de lichia, nesta e na propriedade vizinha, foi irrisória, devido ao grande ataque do ácaro.

Em junho de 2009, muitas galhas, principalmente as mais velhas, estavam cobertas por um micélio de coloração branca. Em laboratório, no exame desse material foi observado um grande número de eriofídeos mortos e envoltos pelo micélio. O material foi encaminhado para o Dr. Marcel Tanzini, que identificou o fungo como Hirsutella thompsonii (Fischer) (Figura 1). Em consequência dessa alta infecção, houve um menor dano de A. litchii, com uma boa produção de frutos no final do ano.

H. thompsonii disseminou-se por todo o pomar, uma vez que o crescimento micelial também foi observado nas demais plantas. É provável que os eríneos formados em consequência da infestação do ácaro tenham proporcionado um microclima favorável para o crescimento desse fungo, talvez por preservar a umidade do ar no interior das galhas. A infecção de $H$. thompsonii é maior em períodos chuvosos apresentando correlação positiva com a pluviosidade e a umidade relativa do ar (DEMITE; FERES, 2008).

Os resultados obtidos sugerem que as galhas provocadas pela infestação dessa praga podem facilitar o desenvolvimento do fungo e a sua permanência nas plantas. Dessa forma, a possibilidade de uso de $H$. thompsonii no controle de $A$. litchi deve ser investigada. 
Figura 1. Hifa de Hirsutella thompsonii com conidióforos e conídios. Foto: Marcel Tanzini.

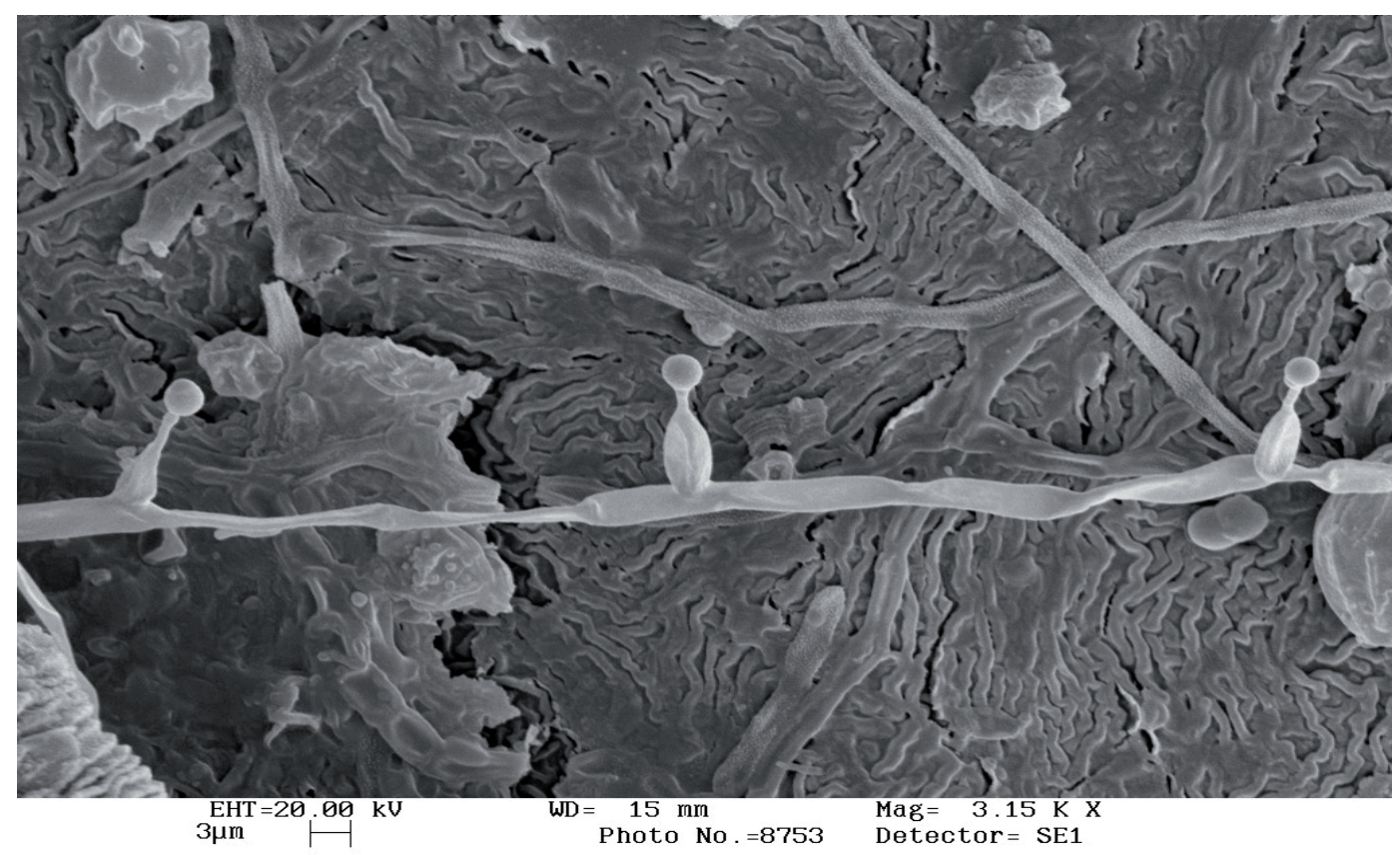

Fonte: Elaboração dos autores.

\section{Agradecimentos}

Os autores agradecem ao Dr. Marcel Tanzini, da Biomax, Piracicaba-SP, pela identificação do fungo H. thompsonii.

\section{Referências}

CENTRO DE PESQUISAS METEOROLÓGICAS E CLIMÁTICAS APLICADAS À AGRICULTURA CEPAGRI. Clima dos municipios paulistas: casa branca. 2011. Disponível em: <http://www.cpa.unicamp.br/ outras-informacoes/clima_muni_124.html>. Acesso em: 31 mar. 2011.

DEMITE, P. R.; FERES, R. J. F. Seasonality of pathogenic fungi in mites of rubber tree plantations adjacent to fragments of Cerrado. Brazilian Journal of Biology, São Carlos, v. 68, n. 3, p. 535-538, 2008.
MARTINS, A. B. G.; BASTOS, D. C.; SCALOPPI JUNIOR, E. J. Lichieira (Litchi chinensis Sonn.). Jaboticabal: Sociedade Brasileira de Fruticultura, 2001. $48 \mathrm{p}$. (Frutas potenciais).

SIDIQQUI, S. B. M. A. B. Lychee production in Bangladesh. In: PAPADEMETRIOU, M. K.; DENT, F. J. (Ed.). Lychee production in the Asia-Pacific region. Bangkok: Food and Agriculture Organization of the United Nations, 2002. p. 28-40.

SINGH, H. P.; BABITA, S. Lychee production in Índia. In: PAPADEMETRIOU, M. K.; DENT, F. J. Lychee production in the Asia-Pacific region. (Ed.). Bangkok: Food and Agriculture Organization of the United Nations, 2002. p. 55-77.

TANZINI, M. R.; ALVES, S. B.; TAMAI, M. A.; MORAES, G. J. de; FERLA, N. J. An epizootic of Calacarus heveae (Acari: Eriophyidae) caused by Hirsutella thompsonii on rubber trees. Experimental and Applied Acarology, Amsterdam, v. 24, n. 2, p. 141-144, 2000. 
